\title{
Development of a PM Linear Motor for Driving HTS Maglev Vehicle
}

\author{
Youguang Guo ${ }^{1}$, Jiaxin Chen ${ }^{2,1}$, Jianguo Zhu ${ }^{1}$, Haiyan $\mathrm{Lu}^{3}$, Haiwei $\mathrm{Lu}^{1}$, Jianxun $\mathrm{Jin}^{4}$ \\ ${ }^{1}$ Faculty of Engineering, University of Technology, Sydney, NSW 2007, Australia \\ ${ }^{2}$ College of Electromechanical Engineering, Donghua University, Shanghai 200051, China \\ ${ }^{3}$ Faculty of Information Technology, University of Technology, Sydney, NSW 2007, Australia \\ ${ }^{4}$ Center of Applied Superconductivity, University of Electronic Science and Technology of China, Chengdu, China
}

\begin{abstract}
The phenomenon that a permanent magnet (PM) over a high temperature superconductor (HTS) bulk can produce strong levitation force with self-stabilizing feature has attracted strong interest of application in maglev transportation systems, in which a linear motion drive is an obvious advantage. This paper presents the development of a PM linear synchronous motor drive for a small-scale prototype vehicle which is levitated by PM-HTS bulks. Magnetic field finite element analyses are conducted to compute accurately the key motor parameters such as winding flux, back electromotive force $(\mathrm{em} f)$, inductance and cogging force. The steady state characteristic of the motor is predicted by using the classic phasor voltage equation, which can provide a reasonable result if the fundamental components of the applied voltage, back emf and current are dominant. A Matlab/Simulink-based model, capable of considering the dependence of key parameters on the mover position, is built to predict effectively the motor's dynamic performance under a brushless DC (BLDC) control scheme. The simulated results show that the developed linear motor can drive the HTS maglev vehicle prototype at the desired speed.
\end{abstract}

\section{INTRODUCTION}

Since the phenomenon that a stable levitation force can be generated by a $\mathrm{NdFeB}$ permanent magnet (PM) over a $\mathrm{YBaCuO}$ high temperature superconductor (HTS) bulk bathed in liquid nitrogen was observed in 1988 [1], a lot of work has been conducted to investigate the potentials of HTS application in various fields, particularly frictionless bearings for flywheel energy storage devices [2] and maglev transportation systems [3, 4]. The main advantage of HTS levitation is the strong levitating force with passive and self-stabilizing feature, leading to the removal of the sophisticated control system for regulating the airgap between guideway and levitated vehicle, which is necessary for other types of levitation transportation systems.

Linear motors are often used for linear motion drives, providing higher efficiency, reliability and positioning accuracy than their rotary counterparts thanks to the absence of movement transformation. Based on our previous work on a linear PM synchronous motor driving system for a small-scale prototype HTS maglev vehicle [5-6], this paper aims to present more detailed performance analysis of the motor drive in both steady and dynamic operations.

For design and performance analysis of the linear motor, magnetic field finite element analysis (FEA) is carried out for accurately calculating the major parameters such as winding flux, back electromotive force (emf), winding inductance, and cogging torque. The classic phasor voltage equation is used to predict the motor's steady state characteristic under the optimal brushless DC control (BLDC) condition, i.e. the back emf is in phase with the stator current. A Matlab/Simulink-based model, capable of taking into account the real curves of key motor parameters against mover position, is compiled to predict effectively the dynamic drive performance. The performance analysis and simulated results show that the linear motor is capable of driving the HTS maglev vehicle prototype at the desired speed.

\section{SMALl-SCAlE MAGLEV Vehicle}

Fig. 1 shows the schematic structure of the developed small-scale maglev vehicle, which is lifted by PM-HTS maglev blocks and is driven by two side linear motors [5-6]. The overall size of the prototype vehicle includes $200 \mathrm{~mm}$ for the length along the movement direction, $50 \mathrm{~mm}$ for the width and $50 \mathrm{~mm}$ for the height.

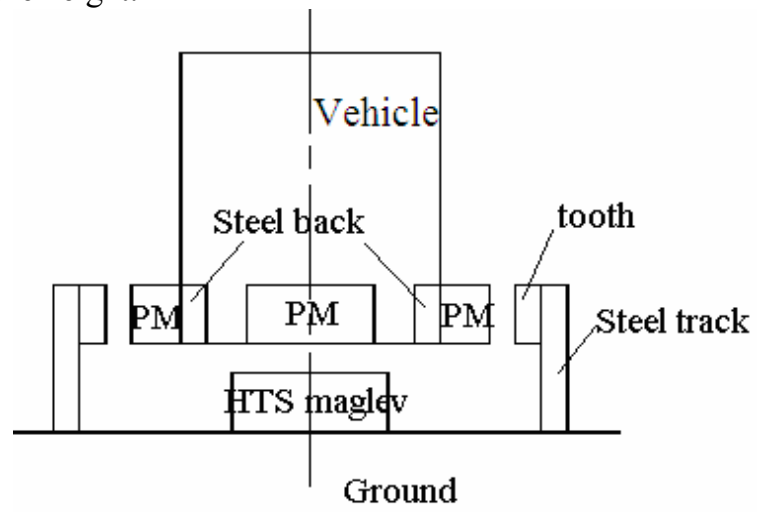

Fig. 1. Schematic diagram of an HTS maglev vehicle prototype

\section{LINEAR MOTOR DRIVE}

While the maglev force is produced by the PM-HTS bulks, the driving force is produced by the interaction of magnetic fields of the PMs mounted on the mover sides and the currents flowing in the coils placed in the slots of stationary sidetracks. The two linear motors, one in each side, can be seen in Fig. 1. The employment of two side motors offers the advantage that the lateral attraction force can be greatly reduced or even be canceled [7]. Fig. 2 plots the motor structure viewed from the top, and Table 1 lists the major dimensions and parameters. 
The coils wound around stator teeth are connected to form 3 phase windings, which are supplied by a standard 3-phase inverter. It can be seen that only the coils facing the mover would produce the driving force, while the others only cause additional resistance, power loss and flux leakage. To deal with this problem, the coils can be divided into sections. The inverter is only connected to the active sections [7].

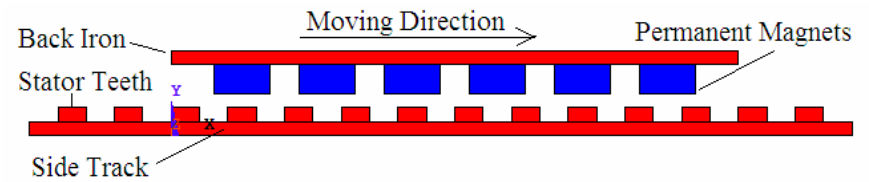

Fig. 2. Top view of the PM linear motor (one side)

TABLE I

MAJOR PARAMETERS AND DIMENSIONS OF THE LINEAR MOTOR (ONE SIDE)

\begin{tabular}{ll}
\hline Dimensions and parameters & Quantities \\
\hline PM length (magnetization direction) $(\mathrm{mm})$ & 10 \\
PM width (movement direction) $(\mathrm{mm})$ & 20 \\
PM height $(\mathrm{mm})$ & 10 \\
Gap between adjacent PMs $(\mathrm{mm})$ & 10 \\
Thickness of PM back iron $(\mathrm{mm})$ & 5 \\
Tooth length $(\mathrm{mm})$ & 5 \\
Tooth width $(\mathrm{mm})$ & 10 \\
Tooth depth $(\mathrm{mm})$ & 10 \\
Slot width $(\mathrm{mm})$ & 10 \\
Main airgap $(\mathrm{mm})$ & 5 \\
Number of turns of stator winding & 35 \\
Diameter of copper wire $(\mathrm{mm})$ & 0.75 \\
Resistance per phase $(\Omega)$ & 0.41 \\
\hline
\end{tabular}

\section{Magnetic Field FEA ANd Parameter CAlculation}

Magnetic field FEA can account for the detailed motor structure and the nonlinear properties of ferromagnetic materials and hence can accurately compute the field distribution and motor parameters. In this paper, two-dimensional field computation in one pole-pair region is carried out, which can be sufficient for theoretical analysis. It should be noted that three-dimensional analysis within the whole motor could be conducted for considering the fringing effect and non-symmetry among three phases, at the expense of longer computational time.

The waveform of PM flux, defined as the winding flux produced by the mover PMs, can be obtained from the no-load field solutions at different mover positions. To increase the computational accuracy and efficiency, the stator and mover are meshed separately from the middle of the airgap. When the mover moves to a specified position, the meshes are stitched along the middle airgap line. Periodical boundary conditions are applied. Fig. 3 shows the PM flux versus the mover position, which is almost sinusoidal.

When the mover moves, an emf is induced in the stator windings. The magnitude of fundamental flux component is computed as $\phi_{I}=0.0948 \mathrm{mWb}$, so the back emf and force constants, $K_{E}$ and $K_{F}$, can be determined as $1.47 \mathrm{Vs} / \mathrm{m}$ and 4.41 $\mathrm{N} /$ A respectively, by

$$
k_{E}=\frac{\pi N_{e} N_{s} \phi_{1}}{\sqrt{2} \tau}
$$

$$
k_{F}=m k_{E}
$$

where $N_{e}=6$ is the number of active coils per phase, $N_{s}$ the number of turns of a coil, $\tau$ the pole pitch, and $m=3$ the number of phases.

By using a modified incremental energy method [8], the self and mutual inductances of the three phase windings are computed as $0.163 \mathrm{mH}$ and $0.062 \mathrm{mH}$, respectively. Due to the large effective airgap in the surface mounted PM motor, the inductances remain constant at different mover positions.

The cogging force can be obtained from the no-load field solutions by the virtual work or the Maxwell stress tensor method. It is found that the cogging force is negligible.

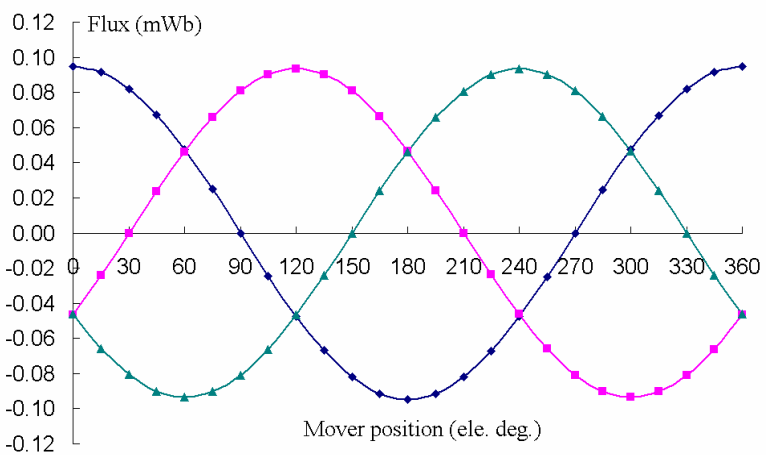

Fig. 3. PM flux of one turn of one coil

\section{STEADY-STATE CHARACTERISTICS}

When the motor operates in synchronous mode, its steady-state characteristics can be predicted by the phasor equation

$$
V_{1}=E_{1}+R_{1} I_{1}+j \omega_{1} L_{1} I_{1}
$$

where $V_{l}, E_{l}$ and $I_{l}$ are rms values of the applied voltage, the induced emf, and the current of a phase winding, respectively, $R_{l}$ is the phase winding resistance, $\omega_{l}$ the angular frequency, and $L_{l}$ the synchronous inductance which equals the self-inductance plus half mutual inductance here.

The motor is assumed to operate in the optimum brushless DC mode, i.e. $I_{l}$ in phase with $E_{l}$, so that the electromagnetic power and force can be calculated by

$$
\begin{gathered}
P_{e m}=m E_{1} I_{1} \\
F_{e m}=P_{e m} / v=K_{F} I_{1}
\end{gathered}
$$

where $v$ is the mover speed, and $E_{l}=K_{E} v$.

For a given terminal voltage, $V_{l}$, the relationship between the mover speed and electromagnetic force is determined by (6). Fig. 4 illustrates the steady-state mechanical characteristics with different phase voltages.

$v=\frac{\sqrt{\left(\frac{R_{1} F_{e m}}{m}\right)^{2}+\left[\left(\frac{\pi L_{1} F_{e m}}{\tau K_{T}}\right)^{2}+K_{E}^{2}\right]\left[V_{1}^{2}-\left(\frac{R_{1} F_{e m}}{K_{T}}\right)^{2}\right]}-\frac{R_{1} F_{e m}}{m}}{\left(\frac{\pi L_{1} F_{e m}}{\tau K_{T}}\right)^{2}+K_{E}^{2}}$ 


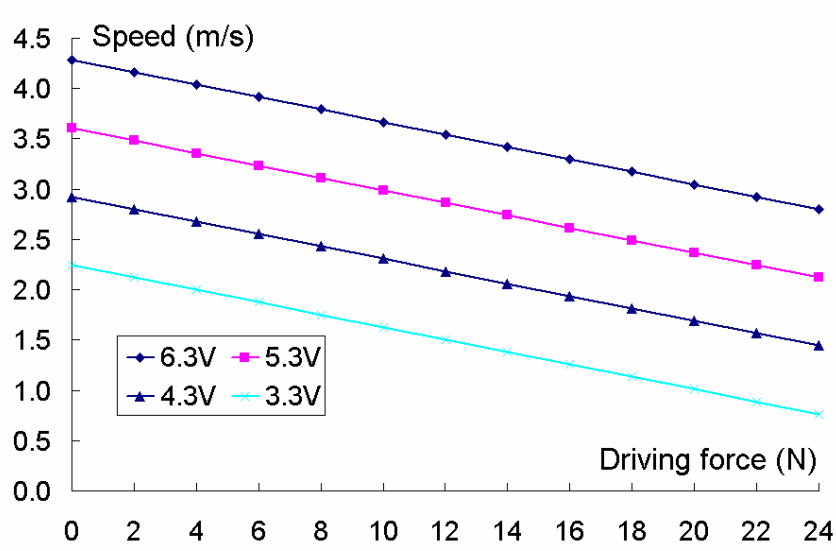

Fig. 4. Steady-state mechanical characteristics of the linear motor

\section{DyNAMIV PERFORMANCE ANALYSIS USING Phase VARIABle MODEL}

The dynamic performance of the linear motor under BLDC control can be analyzed by the following equation-based phase variable model [9-10]:

$$
\begin{gathered}
V_{k}=r_{k} i_{k}+d \lambda_{k} / d t+e_{k}, \quad k=a, b, c \\
\lambda_{k}=\sum_{q=a}^{c} L_{k q} i_{q}
\end{gathered}
$$

$$
\begin{gathered}
F_{e m}=\frac{e_{a} i_{a}+e_{b} i_{b}+e_{c} i_{c}}{v}+F_{c o g} \\
m \frac{d v}{d t}=F_{e m}-B v-F_{L}
\end{gathered}
$$

All above variables are used as their conventional meanings. The profiles of $L, e$ and $F_{c o g}$ can be obtained from a series of nonlinear FEA solutions, in which the mover position dependence and saturation effect are considered.

Suppose the electrical potentials (voltages) of terminals $a, b, c$ and $N$ (the neutral point) of the Y-connected three phase windings are $U_{a}, U_{b}, U_{c}$ and $U_{N}$, respectively, one can obtain

$$
V_{k}=U_{k}-U_{N}, \quad k=a, b, c
$$

Assuming that the hard switching is applied, at the moment when phase $a$ is positively excited and phase $b$ is negatively excited, the following equations can be obtained:

$$
U_{N}= \begin{cases}\frac{1}{3} \sum_{k=a}^{c}\left(U_{k}-E_{k}\right) & i_{c} \neq 0 \\ \frac{1}{2} \sum_{k=a}^{b}\left(U_{k}-E_{k}\right) & i_{c}=0\end{cases}
$$

According to (7)-(12), a Matlab/Simulink-based simulation model can be built to analyze the motor's dynamic performance, as shown in Fig. 5.

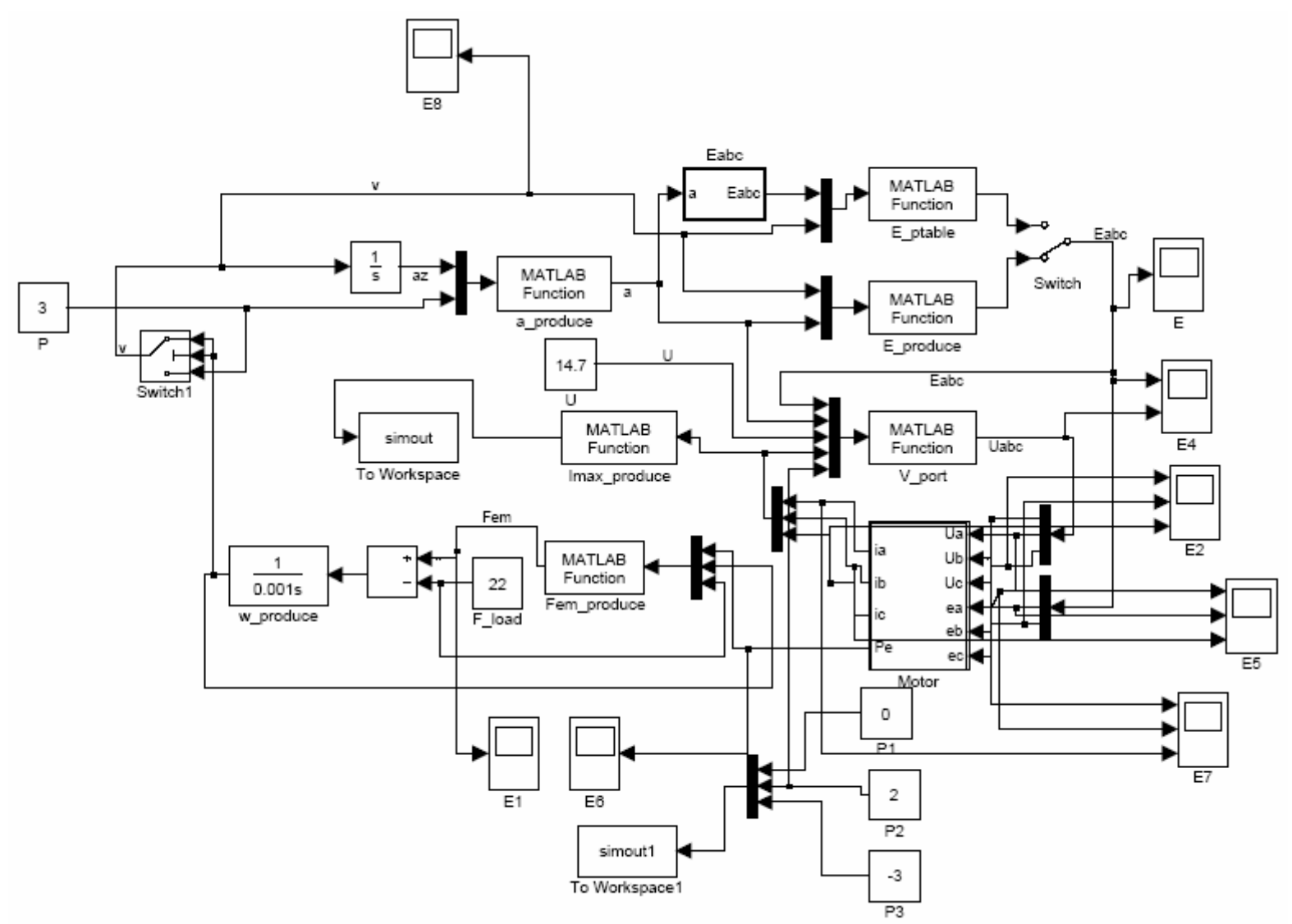

Fig. 5. Matlab/Simulink-based simulation model of the brushless DC motor with sinusoidal back emf 
As an example, Fig. 6 shows the start-up speed curve of the motor with full load when the rated voltage of the inverter is applied. The developed linear motor drive can drive the prototype vehicle at the rated speed of $3 \mathrm{~m} / \mathrm{s}$.

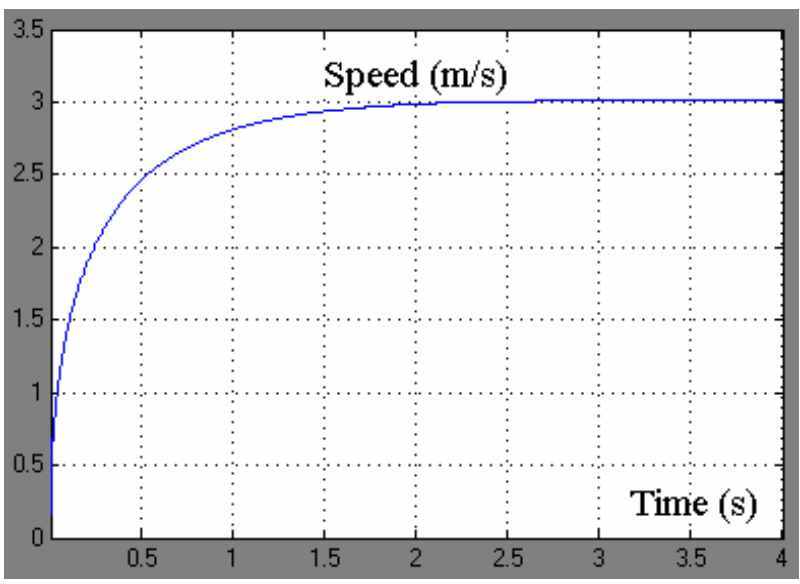

Fig. 6. Speed curve during start-up

\section{CONCLUSION}

This paper presents the performance analysis of a PM linear synchronous motor drive for a small-scale prototype HTS maglev vehicle. Key motor parameters are computed based on nonlinear time-stepping magnetic field finite element analyses. The motor performance is predicted by both the classic phasor voltage equation and a Simulink-based phase variable model. Simulation results show that the developed linear motor drive can successfully drive the maglev vehicle prototype.

\section{REFERENCES}

[1] F. Hellman, E. M. Gyorgy, D. W. Johnson Jr., H. M. O’Bryan, and R. C. Sherwood, "Levitation of a magnet over a flat type II superconductor," $J$. Appl. Phys., vol. 63, pp. 447-450, Jan. 1988.

[2] S. Nagaya, N. Kashima, M. Minami, H. Kawashima, and S. Unisuga, "Study on high temperature superconducting magnetic bearing for $10 \mathrm{kWh}$ flywheel energy storage system," IEEE Trans. Applied Superconductivity, vol. 11, no. 1, pp. 1649-1652, Mar. 2001.

[3] J. Bankuti, I. Vajda, L. Mohacsi, A. Szalay, I. Kotsis, and M. Enisz, "Design and construction of a small-scale model of a high-temperature superconducting magnetically levitated vehicle," IEEE Trans. Magn., vol. 32, no. 4, pp. 2288-2291, July 1996

[4] S. Wang, J. Wang, X. Wang, Z. Ren, Y. Zeng, C. Deng, etc., "The man-loading high-temperature superconducting maglev test vehicle," IEEE Trans. Applied Superconductivity, vol. 13, no. 2, pp. 2134-2137, June 2003.

[5] Y. G. Guo, J. X. Jin, J. G. Zhu, and H. Y. Lu, "Design and performance evaluation of a PM linear synchronous motor for maglev transportation," in Proc. Australasian Universities Power Engineering Conf., Melbourne, Australia, Dec. 10-13, 2006, paper No. TS1-03.

[6] Y. G. Guo, J. X. Jin, J. G. Zhu, and H. Y. Lu, "Design and analysis of a prototype linear motor driving system for HTS maglev transportation," IEEE Trans. Applied Superconductivity, vol. 17, no. 2, pp. 2087-2090, June 2007

[7] G. W. Mclean, "Review of recent progress of linear motors," IEE Proceedings - Part B, vol. 135, no. 6, pp. 380-416, Nov. 1988.

[8] Y. G. Guo, J. G. Zhu, and H. Y. Lu, "Accurate determination of parameters of a claw pole motor with SMC stator core by finite element magnetic field analysis," IEE Proceedings - Electri. Power Appl., vol. 153, no. 4, pp. 568-574, July 2006

[9] O. A. Mohammed, S. Liu, and Z. Liu, "A phase variable model of brushless dc motors based on finite element analysis and its coupling with external circuits," IEEE Tran. Magn., vol. 41, no. 5, pp. 1576-1579, May 2005.

[10] Y. G. Guo, J. G. Zhu, J. X. Chen, and J. X. Jin, "Performance analysis of a permanent magnet claw pole SMC motor with brushless de control scheme," in Proc. Int. Power Electronics and Motion Control Conf., Shanghai, China, Aug. 13-16, 2006. 